At the University of North Carolina a team of investigators measured how much the sounds of jet aircraft would disturb sleep and impair alertness and efficiency next morning. ${ }^{1}$ While volunteers slept in a laboratory sounds of jets flying overhead lasting 20 seconds were played at irregular intervals for a total of nine times per night and at a loudness of 80 decibels. Continuous monitoring of the electrical brain rhythms showed that, compared with control periods, the rhythms after the noises were faster, and remained so for over five minutes, indicating that sleep was lighter. ${ }^{1}$

In the morning the volunteers were required to perform a task in which they had to press one of four buttons to extinguish one of four lights that kept flashing on and in which they had to remember which button corresponded to which light in a relationship that changed at intervals. After nights of aircraft noise the performance of this task was much poorer that after an ordinary night's sleep. Moreover, while the task was being carried out the electrical brain rhythms contained many more slow-wave components, suggesting that the brain was still tired and sleepy.

It is no new thing to discover that loud noises disturb sleep and that after a bad night one is not at one's best, but it is valuable to have actual specific data on aircraft noise. The volunteers were healthy young men, who often had no subsequent recollection of the nocturnal noises. Young men tend to be heavy sleepers and it is older people, especially women, who sleep badly ${ }^{2}$, hence for them the effects of aircraft noise might be expected to be worse. Sleep is, moreover, disturbed to greater degree by sounds that have some personal significance or that have been thought about as important just before sleep. ${ }^{3}$ The sleep disturbance would therefore be greater still in those who felt aggrieved or angry about aircraft noise-a justifiable anger as the results of the experiments showed.

Flying personnel too are liable to disorganized sleep and the 1948 Berlin airlift became jeopardized by aircrew fatigue until resolute action was taken to provide them with quiet suroundings for rest and undisturbed sleep. ${ }^{4}$ In industry, too, shift workers find that they cannot get to sleep so easily when they depart from ordinary times of rest and they are frequently troubled by family and neighbourhood noises when trying to sleep by day. Under these conditions absence from work on account of minor sickness increases. A recent study found that absence for minor, uncertified sickness was highest on a rapidly rotating ("continental") shift rota, ${ }^{5}$ even though this system is one with a reputation for popularity among employees because it avoids long periods during which social customs cannot be followed.

Hospital junior doctors form another group who traditionally may not get enough sleep. In a recent study 14 New York interns were checked for their accuracy and speed in detecting arrhythmias in electro-cardiograms and were offered prizes for good performance. ${ }^{6}$ After nights when they had averaged under two hours of sleep they made twice as many errors and were much slower than after a night of seven hours, as well as feeling more depressed, irritable, and lacking in confidence. Doctors who work in intensive care units know the importance of their own sleep, but sometimes have neglected to provide adequate amounts of it for their patients, ${ }^{78}$ even though rest has long been suspected to help healing. Modern knowledge about sleep suggests that it has a role in fostering synthetic processes for tissue repair. ${ }^{3}$

The brain has an imperative need for rest and sleep, and those who live around airports may suffer in unsuspected ways. Doctors have always been concerned with life and death, but now can join in the growing concern for life's quality, including the provision of peace and quiet. 1 LeVere, T. E., Bartus, R. T., and Hart, F. D., Aerospace Medicine,

2 McGhie, A., and Russell, S. M., fournal of Mental Science, 1962,

3 Oswald, I., Sleep, 2nd ed., 1970. Harmondsworth, Penguin Books.

Stanbridge, R. H., Lancet, 1951, 2, 1.

Pocock, S. J., Sergean, R., and Taylor, P. J., Occupational Psychology, $1972,46,7$.

Friedman, R. C., Bigger, J. T., and Kornfeld, D. S., New England fournal of Medicine, 1971, 285, 201.

H. K., Psychosomatics, Dickstein, K., Lyons, J. W., and Fischer,

Taylo 8, 47.

\section{To Nibble or Gorge?}

The pattern of ingestion of food has a considerable effect on the metabolism and body composition of experimental animals. Some of the experimental observations may apply to man, and the pattern of food intake has been suggested as a possible factor in the pathogenesis of atherosclerosis and coronary heart disease. ${ }^{1}$ While carnivorous animals may eat very infrequently ("gorging"), the normal feeding pattern of most herbivorous animals is "nibbling." If animals which are by nature nibblers are trained to ingest large amounts of food at a time, metabolic adaptations occur in adipose tissue and liver which favour the rapid storage of ingested food as glycogen or fat. When an isocaloric intake is ensured, infrequent feeding results in a net increase of total body fat over that in controls fed ad libitum, ${ }^{2}$ and it has also been observed to induce hypercholesterolaemia in a variety of animal species. ${ }^{3}$

The findings in man are less clear-cut, but there are some indications that we may fare better on a nibbling than on a gorging or conventional meal pattern. Though some investigators have been unable to find any effect of meal frequency on weight reduction during calorie restriction ${ }^{4}$ or on serum lipids, 56 others have reported short-term reductions in levels of serum lipid when the diet, otherwise unchanged, was divided into a greater number of equal portions. ${ }^{13}$ Some studies ${ }^{7}$ have shown an increase of serum lipid levels as well as decreased glucose tolerance in response to a single large daily meal, with reversal of these changes on a nibbling regimen in which the same foods were divided into 10 identical meals per 24 hours. Several epidemiological investigations have tended to corroborate these findings. A study ${ }^{8}$ of the height/weight ratio of children in schools that served three, five, or seven meals showed a tendency to excess weight in the children aged 10 to 16 who were eating three meals. The same workers 9 studying the normal dietary habits of Czechoslovakian men found that the incidence of obesity, hypercholesterolaemia, and diminished glucose tolerance decreased as meal frequency increased. A subsequent population study ${ }^{10}$ was reported to show that the percentage of people in whom ischaemic heart disease was diagnosed decreased with increasing frequency of meals.

But there have been few reports about the influence of food intake patterns on the metabolism of human adipose tissue, and a recently published study by G. A. Bray ${ }^{11}$ is therefore of interest. Biopsy specimens of adipose tissue were obtained from obese persons on a high-calorie diet during both gorging and nibbling regimens, and their 
metabolism was studied in vitro. Rapid ingestion of food was accompanied by an increase in the incorporation of isotope-labelled pyruvate into glyceride-glycerol and fatty acids, as well as by increased activity of glycerol-3-phosphate dehydrogenase. These results suggest enhanced lipogenesis during a gorging regimen. Though the evidence is by no means conclusive, this study provides a further indication that taking infrequent meals may be associated with a tendency to obesity and hyperlipidaemia. The modern Western tendency is to eat a large proportion of the day's calories at one evening meal. Though infrequent feeding is probably not pathogenic in itself, it may become so when combined with a high-calorie intake and a low-energy expenditure. Whether or not the high incidence of atherosclerosis which afflicts man, and which has been correlated with serum lipid levels, can be influenced by alteration of the pattern of food intake is at present unknown, but this question deserves further study.

1 Cohn, C., Federation Proceedings, 1964, 23, 76.

2 Cohn, C., and Joseph, D., Metabolism, 1960, 9, 492.

3 Jagannathan, S. N., Connell, W. F., and Beveridge, J. M. R., American fournal of Clinical Nutrition, 1964, 15, 90 .

Bortz, W. M., Wroldsen, A., Issekutz, B., and Rodahl, K., New England fournal of Medicine, 1966, 274, 376.

Swindells, Y. E., Holmes, S. A., and Robinson, M. F., British Fournal of Nutrition, 1968, 22, 667

Finkelstein, B., and Fryer, B. A., American fournal of Clinical Nutrition, 1971, 24, 465 .

Gwinup, G., Byron, R. C., Roush, W. H., Kruger, F. A., and Hamwi, G. J., American Fournal of Clinical Nutrition, 1963, 13, 209.

Fábry, P., Hejda, S., Cerny, K., Osancová, K., and Pechar, J. American fournal of Clinical Nutrition, 1966, 18, 358.

Fabry, P., Fodor, J., Hejl, Z., Braun, T., and Zvolánková, K., Lancet, 1964, 2, 614

10 Fabry, P., Fodor, J., Hejl, Z., Geizerova, H., and Balcarova, O., Lancet, 1968, 2, 190

11 Bray, G. A., Fournal of Clinical Investigation, 1972, 51, 537.

\section{Toxicity of Thallium}

Thallium is an extremely toxic and cumulative poison. Within three years of its discovery in 1861 a paper was published 1 warning of its toxicity to animals and man. The degree of toxicity has been variously estimated as lying somewhere between that of lead and arsenic. But the recent trial of Graham Frederick Young 2 for poisoning two of his workmates is said to be the first case of homicide by thallium in British legal history.

Like most elements soon after their discovery, the thallium salts have been tried for the treatment of certain chronic inflammatory diseases. They were also used as a temporary depilatory in cases of ringworm of the scalp. But their frequently poisonous effects led to thallium therapy being abandoned. The difficulty is that the therapeutic dose is too close to the lethal dose. E. Browning ${ }^{3}$ gives the therapeutic dosage as being $8 \mathrm{mg}$ of thallium acetate per $\mathrm{kg}$ bodyweight, while $12 \mathrm{mg}$ per $\mathrm{kg}$ is the minimum lethal dose for an adult.

But in industry the use of thallium is increasing. Because of its high refractive index it is incorporated into the manufacture of optical lenses, in infra-red optical instruments, and in imitation precious jewellery. It is used in alloys along with silver and lead, serves as a catalyst in a number of organic reactions, and has also been included in fireworks. Recently thallium salts have been used in the crystals which serve as scintillation counters. But it is in the form of rodenticides and insecticides that thallium constitutes the main hazard to the general public.

Thallium salts can enter the body in three ways-by inhalation as a dust, by ingestion either from contaminated food or from the hands, or by absorption through the skin. J. C. Munch ${ }^{4}$ examined the reports of 12 non-fatal cases of industrial poisoning and established that the main symptoms were fatigue, limb pains, and loss of hair. More severe poisoning results in peripheral neuritis, proteinuria, and joint pains, but occasionally neurological signs are the presenting factors. A striking example of non-industrial poisoning was described by Munch and colleagues 5 in 1933 from California. At least 30 people accidentally ate barley grain impregnated with $1 \%$ thallium sulphate intended as a rodenticide. Six died of acute thallitoxicosis within 16 days and a seventh two months later; and 20 persons developed gastroenteritis, abdominal colic, peripheral neuritis, strabismus, disorientation, convulsions, joint pains, and alopecia, mostly within three days. A similar accident involving nine members of three families occurred, despite warnings, in Mexico in 1964.

Recently W. J. Bank and colleagues ${ }^{6}$ studied five patients with thallium intoxication, two of whom were children who had eaten poisoned bait. All of them developed neurological symptoms, and alopecia was present in four of the five. They stress the importance of including thallium in the differential diagnosis when early bizarre neurological signs present themselves. Furthermore they advocate the use of a simple screening test of urine for thallium salts.

The treatment of thallium poisoning poses some difficulties. The principle is to increase urinary and faecal excretion, though the rate of each is slow. Chelating agents have been proposed, but results with these have been inconstant. 7 In addition potassium chloride is useful, but Bank and colleagues ${ }^{6}$ point out that such a regimen is limited by the amount of thallium that can be released into the blood without worsening the symptoms. However, it is probably the better method of treatment of the two.

While thallium salts continue to be used as rodenticides the danger of accidental poisoning, especially to children, will continue to exist. So long as the hazard remains, its possibility should be borne in mind in all cases of unexplained neurological symptoms and peripheral joint pains. The early use of a screening test on the urine would appear to be far better than waiting to see if the hair falls out.

\footnotetext{
1 Grandeau, L., fournal Anatomie Physiologie Normales Pathologiques Homme et Animaux, 1864, 1, 378

2 British Medical fournal, 1972, 3, 70.

3 Browning, E., Toxicity of Industrial Metals, 2nd edn. London, Butterworth, 1969.

Munch, J. C., Fournal of the American Medical Association, 1934, 102, 1929. Munch, J. C., Ginsburgh, H. M., and Nixon, C. E., Fournal of the American Medical Association, 1933, 100, 1315

- Bank, W. J., Pleasure, D. E., Suzuki, K., Nigro, M., and Katz, R., Archives of Neurology, 1972, 26, 456.

7 Sunderman, F. W., Paynter, O. E., and George, R. B., American fournal of the Medical Sciences, 1967, 254, 24.
}

\section{Urinary Incontinence in Women}

The diagnosis of stress incontinence is often difficult. It requires differentiation from frequency, urgency. and urge incontinence, and even very rarely from true incontinence due to a small urinary fistula.

The abnormality underlying the symptom is not always clear, for even the famed loss of the posterior urethrovesical angle, seen by cine-radiography, is not present in 